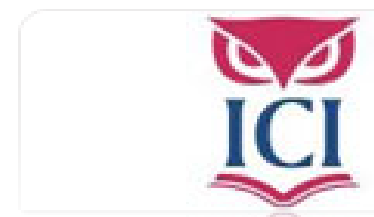

IUS. Revista del Instituto de Ciencias Jurídicas de Puebla A.C.

ISSN: 1870-2147

revista.ius@hotmail.com

Instituto de Ciencias Jurídicas de Puebla A. C.

México

Carbonell, Miguel

DERECHOS FUNDAMENTALES Y RELACIONES ENTRE PARTICULARES (NOTAS PARA SU ESTUDIO)

IUS. Revista del Instituto de Ciencias Jurídicas de Puebla A.C., núm. 18, 2006, pp. 50-75 Instituto de Ciencias Jurídicas de Puebla A. C.

Puebla, México 


\section{DERECHOS FUNDAMENTALES Y RELACIONES ENTRE PARTICULARES (NOTAS PARA SU ESTUDIO)}

Dr. Miguel Carbonell*

\section{SUMARIO:}

I. LA POSTURA TRADICIONAL Y SUS INSUFICIENCIAS II. La Situación EN EL ORdenamiento JURídico mexicano III. El LUgar del PRINCIPIO dE AUtONOMIA dE LA VOLUNTAD IV. DesarRollo JuRISPRUdencial V. Derecho comparado y derecho internacional de loS Derechos humanos

\section{LA POSTURA TRADICIONAL Y SUS INSUFICIENCIAS}

Tradicionalmente, los derechos fundamentales se han concebido como posiciones jurídicas que los particulares podían oponer solamente a los poderes públicos. Esta idea es en gran parte deudora del contexto histórico en el que surgen los derechos y de su posterior desarrollo doctrinal. Por lo que hace al contexto histórico, hay que recordar que las primeras declaraciones de derechos nacen como una reacción contra el "Estado absolutista", contra los regímenes monárquicos que negaban a sus súbditos los más elementales derechos y que ejercían el poder de manera despótica; el enemigo a vencer en ese entonces, a finales del siglo xviII, era el aparato estatal y lo que se intentaba proteger era la sociedad civil.

Para esta visión, por tanto, no era concebible que las amenazas a los derechos pudieran venir justamente de la arena de los propios oprimidos, es decir, de los particulares. En este contexto, resulta comprensible que las primeras declaraciones de derechos hicieran un énfasis muy significativo en los derechos de libertad entendidos como esferas de los particulares inmunes frente a todo tipo de actuación estatal. ${ }^{1}$

* Investigador del Instituto de Investigaciones Jurídicas de la UNAM.

${ }^{1}$ Cfr. al respecto, Carbonell, Miguel, Una historia de los derechos fundamentales, unAm, Porrúa, CNDH, México, 2005. 
Este esquema tradicional es explicado y desarrollado por la que se conoce como "teoría liberal" de los derechos, según la cual cada persona tiene protegida una esfera intraspasable para los poderes públicos que le asegura la posibilidad de conducirse como lo prefiera en muchos ámbitos de su existencia.

Pedro de Vega apunta que la teoría clásica de los derechos fundamentales fue planteada "desde las hipotéticas tensiones entre el individuo y el Estado, entendiendo que era sólo el poder estatal el que podía conculcarlos. Hablar desde esas perspectivas de un recurso de amparo frente a posibles lesiones de los derechos fundamentales producidas por los particulares sujetos de derecho privado no pasaría, por lo tanto, de constituir un fenomenal despropósito". ${ }^{2}$ El mismo autor agrega, para demostrar la insuficiencia de la teoría jurídica tradicional en este punto, la siguiente afırmación: "la coherente y armónica construcción en la que cimentó su estructura el edificio jurídico liberal fue patéticamente destrozada por la historia".

Con el paso del tiempo los análisis de los derechos fundamentales se han ido haciendo más refinados, lo que ha conllevado el abandono de algunas ideas tradicionales. Esta evolución ha permitido, entre otras cuestiones, poner de manifiesto las insuficiencias y limitaciones de la teoría liberal de los derechos, como ya lo apuntaba Pedro de Vega en la frase que se acaba de transcribir. Por un lado, hoy en día se entiende que, en efecto, muchas amenazas a los derechos siguen proviniendo de los poderes públicos, pero que también son estos mismos poderes los únicos que pueden contribuir a la satisfacción de muchos de nuestros derechos fundamentales; es decir, hoy en día el Estado no es visto tanto o tan sólo como un enemigo de los derechos sino como un aliado de la sociedad en la consecución de los mismos, siempre que se trate de un Estado democrático, desde luego.

Así por ejemplo, es obvio que la realización práctica de los derechos sociales (educación, vivienda, salud, trabajo, menores de edad, personas adultas mayores, personas con discapacidad, etcétera) no puede quedar librada a lo que dispongan o quieran hacer las fuerzas de la sociedad civil, dominadas en muy amplia medida por la lógica del mercado (oferta, demanda, rendimientos, ganancias, intereses, etcétera); en estos ámbitos, el interés general de la sociedad requiere de una acción amplia y decidida por

${ }^{2}$ Pedro de Vega, "La eficacia frente a particulares de los derechos fundamentales (La problemática de la drittwirkung der grundrechte)", en Carbonell, Miguel (Coord.), Derechos fundamentales y Estado. Memoria del VII Congreso Iberoamericano de Derecho Constitucional, unAM, México, 2002, pp. 693-694. ${ }^{3}$ Pedro de Vega, Op. cit., p. 694. 
parte del Estado, que se viene a convertir en el garante de los derechos.

Por otro lado, también nos hemos dado cuenta que no todo lo que se puede clasificar dentro del rubro "sociedad civil" es positivo para los derechos. Por el contrario, hoy en día muchas amenazas a nuestros bienes básicos provienen no tanto de la acción del Estado como de la actuación de otros particulares (con frecuencia amparados por la complicidad de las autoridades, como suele suceder en el caso de México). ${ }^{4}$

Pensemos por ejemplo en el derecho a un medio ambiente sano; ¿quién tiene mayor capacidad de destrucción del ambiente, las autoridades o las grandes empresas? Podemos poner un ejemplo distinto sobre el derecho a la igualdad: ¿la discriminación en nuestras sociedades -la exclusión de una persona por tener un determinado color de piel, por ser mujer, por pertenecer a un pueblo indígena, por tener una discapacidad- se produce solamente por la acción de los órganos públicos o también por los particulares? ¿Cuando una persona se niega a alquilarle una vivienda a otra esgrimiendo como motivo las creencias religiosas del solicitante o cuando una mujer es despedida de su trabajo en una empresa por estar embarazada estamos o no frente a una discriminación y, en consecuencia, frente a una violación de derechos fundamentales realizada por particulares?

Podemos añadir algunos elementos más que acreditan la insuficiencia de la visión liberal tradicional de los derechos fundamentales, elementos que son "contextuales", por llamarlos de alguna manera. Por ejemplo, debe tenerse en cuenta el creciente poder de las corporaciones en nuestras sociedades. Las corporaciones y su absoluto dominio de esferas completas de la actividad económica (en régimen de monopolio o de oligopolio) han pulverizado el mito de la "autonomía de la voluntad", según el cual las relaciones entre particulares estarian significadas por un acuerdo entre per-

\footnotetext{
${ }^{4}$ Sobre este punto Diego Valadés afirma: "El Estado representó una amenaza real para la libertad y la autonomía de las personas; pero hoy los individuos se encuentran expuestos a un doble fuego: el del Estado y el de otros particulares. El poder de éstos se ha dilatado casi en la proporción en que las potestades públicas han disminuido." Cfr. La protección de los derechos fundamentales frente a particulares, scjn, México, 2005, p. 8. En palabras de Juan María Bilbao, "Los poderes privados constituyen hoy una amenaza para el disfrute efectivo de los derechos fundamentales no menos inquietante que la representada por el poder público. Y esto no es retórica, como insinúan algunos. No sólo son temibles por su capacidad para imponer su propia voluntad en el marco de una concreta relación jurídica, sino que pueden resultar incluso más peligrosos que los públicos, ya que gozan en ocasiones de una relativa impunidad, que se ve favorecida por las dificultades existentes para articular un sistema incisivo de control (basta pensar en la problemática fiscalización de la actividad interna de los partidos políticos o de los sindicatos)". Ver Bilbao Ubillos, Juan María, La eficacia de los derechos fundamentales frente a particulares. Análisis de la jurisprudencia del Tribunal Constitucional, CEPC, BOE, Madrid, 1997, p. 243.
} 
sonas situadas en un plano de igualdad que gozaban de amplios márgenes de libertad para celebrar acuerdos conforme a sus mejores intereses. ${ }^{5}$

Hoy en día es obvio que los particulares difícilmente pueden oponerse a las propuestas contractuales que muchas corporaciones presentan en forma de "contratos de adhesión", es decir, como acuerdos de voluntad en los que las cláusulas están dictadas por una de las partes y la otra solamente tiene la opción de aceptarlas o quedarse sin un servicio público de interés general. Pensemos en los casos de los servicios de telefonía, agua potable (en aquellas comunidades en los que este servicio público esté concesionado a empresas particulares, como sucede en varios municipios de México), ${ }^{6}$ gas doméstico, etcétera. Por esto es que tiene toda la razón Pedro de Vega cuando afirma que:

Obligados los hombres, por un lado, a desarrollar su existencia en los ámbitos de las corporaciones y los grupos que conforman el tejido social, y constreñidos, por otro lado, a aceptar la disciplina que esas corporaciones les imponen, la relación poder-libertad no podrá ya ser interpretada en los términos en que restrictivamente lo hacia el constitucionalismo clásico. La aparición en el seno de la sociedad corporatista de poderes privados, capaces de imponer su voluntad y su dominium con igual o mayor fuerza que los poderes públicos del Estado determina... un nuevo y más amplio entendimiento de la dialéctica poder-libertad.?

El mismo autor concluye, con base en este análisis, que si procedemos con elemental coherencia,

la protección de los derechos fundamentales y la actuación de sus sistemas de garantias, no deberá reducirse a contemplar solamente las hipotéticas violaciones de los mismos procedentes de la acción de los poderes públicos, sino que habrá que tener en cuenta también las posibles lesiones derivadas de la acción

\footnotetext{
5 "Detrás de estos supuestos de concentración o monopolización del poder social, económico o informativo... se esconde la privilegiada posición de ciertos individuos u organizaciones cuyo predominio anula o compromete gravemente ese mínimo de libertad e igualdad que constituye el presupuesto de la autonomía privada." Ver Bilbao Ubillos, Juan María, Op. cit., p. 244.

${ }^{6}$ Y peor todavía: cuando un sujeto abusa de una posición dominante para cortar ilegalmente el suministro de agua de una o varias viviendas; la Corte Constitucional colombiana ha resuelto algún procedimiento de acción de tutela sobre un supuesto de este tipo. Al respecto, Cifuentes, Eduardo, La eficacia de los derechos fundamentales frente a particulares, 11J-unAm, México, 1998, p. 34.

${ }^{7}$ Pedro de Vega, $O p$. cit., p. 694. En el mismo sentido, Juan María Bilbao afirma que "La presunción de igualdad entre las partes implicadas en un negocio jurídico privado no puede sostenerse. No son pocos los negocios jurídicos realizados bajo el imperativo de una fuerza desigual... Es un hecho constatable la progresiva multiplicación de los centros de poder en este ámbito (grupos de presión, grandes empresas, confesiones religiosas y otras entidades cuasi-públicas) y la enorme magnitud que han adquirido algunos de ellos. El poder ya no está concentrado en el aparato estatal, está disperso, diseminado en la sociedad.” Cfr. Bilbao Ubillos, Juan Maria, Op. cit., pp. 241-242.
} 
de los particulares que, operando desde posiciones de privilegio y configurándose como auténticos poderes privados, emulan en ocasiones con ventaja al propio poder público en su capacidad erosiva y destructora de la libertad. ${ }^{8}$

\section{LA SITUACIÓN EN EL ORDENAMIENTO JURÍDICO MEXICANO}

A nivel teórico se ha defendido durante décadas por una parte de la doctrina constitucional mexicana la idea de que los derechos fundamentales establecen relaciones jurídicas entre los particulares (sujeto activo, titular del derecho en cuestión) y las autoridades (sujeto pasivo, obligado a respetar el contenido del derecho); así, por ejemplo, Ignacio Burgoa afirma que "La relación jurídica de supra a subordinación en que se manifiesta la garantía individual consta de dos sujetos, a saber, el activo o gobernado y el pasivo, constituido por el Estado y sus órganos de autoridad". ${ }^{9}$ De forma congruente con este punto de vista, la Constitución en el artículo 103 fracción I y la Ley de Amparo en su artículo 1 fracción I disponen que el amparo procede solamente contra "actos de autoridad" que violen las garantías individuales.

A nivel jurisprudencial se ha considerado, en consonancia con los dos artículos que se acaban de mencionar, que solamente contra actos de autoridad se puede promover el juicio de amparo; la jurisprudencia tradicional sobre el concepto de autoridad para efectos de amparo es la siguiente:

AUTORIDADES. El término "autoridades", para los efectos del amparo, comprende a todas aquellas personas que disponen de la fuerza pública, en virtud de circunstancias, ya legales, ya de hecho, y que, por lo mismo, estén en posibilidad material de obrar como individuos que ejerzan actos públicos, por el hecho de ser pública la fuerza de que disponen... (Semanario Judicial de la Federación, Quinta Época, tomo Iv, p. 1067) ${ }^{10}$

Con este punto de vista jurisprudencial se cerraba el círculo: ni teóricamente ni en la práctica tenía sentido plantear que los particulares pudieran

\footnotetext{
${ }^{8}$ Ibid., p. 697.

${ }^{9}$ Las garantías individuales, 32a edición, Porrúa, México, 2002, p. 168.

${ }^{10}$ Este criterio ha sido parcialmente modificado, aunque sin consecuencias para el tema que nos ocupa, por la tesis “AUTORIDAD PARA EFECTOS DE JUICIO DE AMPARO. LO SON AQUELLOS FUNCIONARIOS DE ORGANISMOS PÚBLICOS QUE CON FUNDAMENTO EN LA LEY EMITEN ACTOS UNILATERALES POR LOS QUE CREAN, MODIFICAN O EXTINGUEN SITUACIONES JURIDICAS que afectan la esfera legal del gobernado", Tesis xxvi1/97 del Pleno de la Suprema Corte de Justicia de la Nación, cuyo texto completo puede verse en Zaldívar, Arturo, Hacia una nueva ley de amparo, unAm, México, 2002, pp. 71-72.
} 
violar los derechos fundamentales de otros particulares. ${ }^{11}$

Éste es el escenario en el que nuestro análisis debe desenvolverse, si bien es necesario apuntar una cuestión general relevante. Aunque en los párrafos anteriores se ha hecho una breve referencia a la concepción doctrinal o teórica y enseguida se han mencionado los aspectos normativos y jurisprudenciales que impiden plantear un juicio de amparo contra violaciones de los derechos cometidas por particulares, en realidad no se puede perder de vista que ambas cuestiones son distintas y no deben en ningún momento llegar a confundirse. Para decirlo de otra manera: por una parte hay que analizar nuestra concepción (sustantiva) de los derechos fundamentales y determinar si se pueden aplicar o no a las relaciones entre particulares. Por otro lado hay que discutir -si se acepta que los particulares también pueden violar derechos fundamentales- los mecanismos (procesales) necesarios para evitar o reparar esas violaciones.

Si no mantenemos estas dos cuestiones separadas (conceptual y normativamente) estaremos incurriendo en el error tan criticado por Luigi Ferrajoli de confundir los derechos y las garantías. Como ha demostrado en muchos de sus trabajos Héctor Fix Zamudio, el concepto de garantía no puede ser equivalente al de un derecho. La garantía es el medio, como su nombre lo indica, para garantizar algo, para hacerlo eficaz, para devolverlo a su estado original en caso de que haya sido tergiversado, violado, no respetado. En sentido moderno una garantía constitucional tiene por objeto reparar las violaciones que se hayan producido a los principios, valores o disposiciones fundamentales. ${ }^{12}$ Luigi Ferrajoli señala que: "Garantía es una expresión del léxico jurídico con la que se designa cualquier técnica normativa de tutela de un derecho subjetivo." ${ }^{13}$

Ha sido precisamente Ferrajoli quien con mayor agudeza ha explorado los alcances del concepto de "garantía", partiendo de la mencionada idea de que no es lo mismo que un derecho fundamental.

Para Ferrajoli las garantías, en una primera acepción, serían las obligaciones que derivan de los derechos; de esta forma, puede haber garantías positivas y garantías negativas; las negativas obligarian a abstenciones por parte del Estado y de los particulares con respeto a algún derecho

${ }^{11}$ La crítica a las insuficiencias y lagunas del concepto de autoridad y de acto de autoridad para efectos de amparo pueden verse en Zaldivar, Arturo, $0 p$. cit., pp. $65 s s$.

${ }^{12}$ Héctor Fix Zamudio, "Breves reflexiones sobre el concepto y el contenido del derecho procesal constitucional”, en Ferrer MacGregor, Eduardo (Coord.), Derecho procesal constitucional, tomo 1, 4ª edición, Porrúa, México, 2003, pp. 273 y 283, entre otras.

${ }^{13}$ Luigi Ferrajoli, “Garantías”, Jueces para la Democracia, número 38, Madrid, julio de 2002, p. 39. 
fundamental, mientras que las positivas generarían obligaciones de actuar positivamente para cumplir con la expectativa que derive de algún derecho. Estos dos tipos de garantías pueden subsumirse en lo que el mismo autor llama las "garantías primarias o sustanciales", que son distintas de las "garantías secundarias o jurisdiccionales".

Las garantías primarias son precisamente las obligaciones o prohibiciones que corresponden a los derechos subjetivos establecidos en algún texto normativo; por su lado, las garantías secundarias son las obligaciones que tienen los órganos judiciales de aplicar la sanción o declarar la nulidad cuando constaten, en el primer caso, actos ilícitos y, en el segundo, actos no válidos que violen los derechos subjetivos y por tanto violen también las garantías primarias. ${ }^{14}$

La confusión entre los derechos fundamentales y las garantías individuales ha alcanzado también a la jurisprudencia, como puede verse en la siguiente tesis, bien expresiva de la falta de coherencia terminológica con la que se suele abordar la cuestión:

Garantias Individuales. No son derechos sustantivos, sino que constituyen el instrumento constitucional para salvaguardar éstos. Las garantias individuales que se encuentran consagradas en los artículos 14 y 16 constitucionales, como lo son la del debido proceso y la de fundamentación y motivación en todo acto de autoridad, como su nombre lo indica, garantizan la aplicación de la ley en cuanto a los procedimientos seguidos ante tribunales, con el objeto de proteger la integridad física, la libertad y los bienes, siendo éstos, los derechos fundamentales del gobernado, entre otros; es decir, las garantías individuales, no son derechos sustantivos, sino que constituyen el instrumento constitucional establecido por la propia Norma Fundamental del pais, para salvaguardar tales derechos. (Tesis aislada. Semanario Judicial de la Federación y su Gaceta, Tomo IV, octubre de 1996. Novena Época. Tribunales Colegiados de Circuito. Tesis I. $6^{\circ}$. C.28 K. p. 547)

Para la correcta comprensión de los efectos entre particulares de los derechos fundamentales, es preciso no confundir la parte sustantiva con la procesal, ya que si lo hacemos podemos caer en un razonamiento erróneo del siguiente tipo: toda vez que no hay una vía de protección procesal que permita prevenir o reparar las violaciones de los derechos fundamentales realizadas por los particulares, entonces es obvio que tales derechos no pueden hacerse valer más que frente a un acto de autoridad. Con ello se estaría descalificando -a través de argumentos procedimentales- la posi-

${ }^{14}$ Ibid., p. 40. 
bilidad - sustantiva- de comprender el sentido normativo de un derecho fundamental y su proyección a las relaciones jurídicas entre particulares.

Javier Mijangos dice de otra forma y mejor lo que se acaba de apuntar. Para Mijangos hay tres problemas en la temática que estamos estudiando que requieren de un análisis por separado; los tres problemas son el de la construcción, el de la protección y el de la colisión. El primero de ellos, que se puede identificar con lo que hemos llamado "discusión sustantiva", se refiere a la forma en cómo influyen los derechos fundamentales en las relaciones entre particulares; para resolverlo hace falta acudir a elementos como la normatividad de la Constitución, las distintas funciones de los derechos fundamentales, etcétera. ${ }^{15} \mathrm{El}$ segundo problema, referido a la protección, tiene que ver con la procedencia de una garantía judicial frente a las violaciones de derechos realizadas por particulares; se trata, afirma Mijangos, de un problema procesal. ${ }^{16}$ El problema de la colisión se refiere -dice Mijangos- al análisis de los supuestos en que diversos derechos fundamentales pueden verse enfrentados con otros derechos o con bienes protegidos constitucionalmente. ${ }^{17}$

A modo de conclusión provisional podemos señalar que frente a la visión tradicional de los poderes públicos como únicos sujetos pasivos posibles dentro de la relación jurídica derivada de los derechos fundamentales, hoy surge un punto de vista alternativo que nos llama la atención sobre los "poderes salvajes" que existen en las sociedades contemporáneas, tanto en la esfera del mercado como en los ámbitos sociales no regulados. ${ }^{18}$

A partir de esta nueva realidad (que quizá no es nueva, pero de la que la teoría constitucional se ha dado cuenta recientemente) se ha desarrollado una concepción distinta de los derechos fundamentales, desde la que se puede hablar de los "efectos horizontales" de los derechos fundamentales o de la "eficacia entre particulares" de estos mismos derechos.

Se trata de una cuestión bastante compleja que ha sido objeto de un número creciente importante de estudios y monografías, ${ }^{19}$ pero que todavía

\footnotetext{
${ }^{15}$ Javier Mijangos y González, La vigencia de los derechos fundamentales en las relaciones entre particulares, Porrúa, México, 2004, p. xIV.

${ }^{16}$ Ibid., p. xv.

${ }^{17}$ Idem.

${ }^{18}$ En este sentido, además de la bibliografía que ya se ha citado, ver Ferrajoli, Luigi, "Contra los poderes salvajes del mercado: para un constitucionalismo de derecho privado", en Varios autores, Estrategias y propuestas para la reforma del Estado, 2a edición, 11J-UnAm, México, 2002, pp. 99ss.

${ }^{19}$ Las dos obras más importantes en la materia que se han publicado en español son: Bilbao Ubillos, Juan María, La eficacia de los derechos fundamentales frente a particulares. Análisis de la jurisprudencia del Tribunal Constitucional, y Julio Estrada, Alexei, La eficacia de los derechos fundamentales entre particulares, Universidad Externado de Colombia, Bogotá, 2000. También puede ser interesante
} 
representa una cuestión nueva y poco explorada del derecho constitucional, sobre todo en México. ${ }^{20}$

En cualquier caso, quizá pueda ser útil poner algunos ejemplos de nuestro texto constitucional para comprender de qué manera los particulares están obligados por sus mandatos. ${ }^{21}$

El párrafo segundo del artículo 1 constitucional se refiere a la prohibición de esclavitud. ¿Podríamos decir que ese precepto solamente puede ser violado por las autoridades? Parece obvio que no.

El artículo 3 contempla diversos aspectos del derecho a la educación, entre los que se encuentra el señalamiento de que la educación preescolar, primaria y secundaria son obligatorias. ¿No se configura una violación de ese mandato cuando una escuela particular expulsa a un alumno indebidamente (por ejemplo, utilizando alguno de los criterios prohibidos por el artículo 1 párrafo tercero constitucional o si no le da derecho de audiencia al propio alumno o a sus representantes legales)?

¿No podríamos considerar una violación a un derecho fundamental el que una escuela particular no respete el mandato de la fracción I del mismo artículo 3 constitucional que señala que la educación básica obligatoria será laica? ¿Tiene sentido sostener que dicha norma obliga solamente a las autoridades?

El artículo 2 apartado A fracción II de la Constitución se refiere a los derechos de autonomía de los pueblos y comunidades indígenas; concretamente esa fracción contempla el derecho de tales comunidades a aplicar sus propios sistemas normativos en la regulación y solución de sus conflictos internos, pero señala que en esa aplicación deberán respetarse -entre otras cuestiones- la dignidad e integridad de la mujer. De nuevo podemos preguntarnos: ¿esa norma puede o no ser violada por los particulares?

Lo mismo puede decirse acerca del derecho a la procreación del artículo 4 párrafo segundo. La libertad de toda persona de tener el número de hijos con el espaciamiento que considere, ¿obliga solamente a las autoridades?

consultar los ensayos de Hesse, Konrad, Derecho constitucional y derecho privado, Civitas, Madrid, 1995 y Von Münch, Ingo, “Drittwirkung de derechos fundamentales en Alemania”, en Salvador Coderch, Pablo (Coord.), Asociaciones, derechos fundamentales y autonomía privada, Civitas, Madrid, 1997, además del resto de obras citadas en el presente trabajo.

${ }^{20}$ Esto se debe, en general, a que la problemática de los derechos fundamentales frente a particulares nos exige, como lo ha señalado Pedro de Vega, "un cambio radical en el entendimiento de la problemática constitucional". Cfr. De Vega, Pedro, "La eficacia frente a particulares de los derechos fundamentales (La problemática de la drittwirkung der grundrechte)”, Op. cit., p. 697.

${ }^{21}$ Un ejercicio parecido, en referencia al ordenamiento constitucional español, puede verse en Bilbao Ubillos, Juan María, La eficacia de los derechos fundamentales frente a particulares. Análisis de la jurisprudencia del Tribunal Constitucional, pp. 356ss. 
De igual manera, el derecho al medio ambiente o los derechos de los menores de edad (artículo 4, párrafos cuarto y sexto a octavo, respectivamente), suponen mandatos que deben respetar los particulares. Podemos convenir en que un particular no está -en términos generales- obligado a plantar árboles para reforestar un jardín público, pero al menos tiene el deber de abstenerse de empeorar la situación medioambiental cortando árboles.

Un ejemplo claro en el mismo sentido se produce en materia laboral. Tanto los mandatos del artículo 5 constitucional como los del artículo 123 de la propia Carta Magna deben hacerse valer, si queremos que cobren plenitud de sentido, frente a particulares.

Podemos ubicar en una situación análoga -si bien en cada caso habría que aportar ciertos matices, cuando sean necesarios- a la libertad de expresión, la libertad de imprenta, el derecho de réplica o rectificación (que, de hecho, casi solamente se puede hacer valer frente a particulares, en tanto que tienen tal calidad los medios de comunicación), el derecho a la intimidad, el derecho al honor, el derecho a la propia imagen, la libertad de asociación, la libertad de tránsito, la libertad religiosa, las libertades en materia económica, el derecho a la información, la inviolabilidad del domicilio, la inviolabilidad de comunicaciones privadas, el derecho de propiedad, el derecho a la vivienda, el derecho al agua, etcétera.

En sentido contrario, es obvio que hay diversos derechos fundamentales que en nada obligan a los particulares, sino que están dirigidos única y exclusivamente a las autoridades. Tal es el caso, por mencionar un ejemplo obvio y hasta cierto punto absurdo, de la prohibición de retroactividad de las leyes, establecida en el párrafo primero del artículo 14 constitucional; en virtud de que solamente las autoridades pueden emitir leyes (artículos 70, 71 y 72 constitucionales, para el caso del Congreso de la Unión), los particulares no tienen forma ni de cumplir ni de violar tal precepto.

Lo mismo puede decirse en relación al derecho de petición, respecto del cual el artículo 8 de la Constitución señala que puede hacerse valer solamente frente a las autoridades. ${ }^{22}$

En sentido parecido pueden citarse todos aquellos derechos fundamentales referidos al funcionamiento de algún órgano público. Por ejemplo por lo que hace a las detenciones (artículo 16), a los actos de molestia y

\footnotetext{
${ }^{22}$ Hay sin embargo un precedente interesante en Colombia que reconoce que este derecho puede hacerse valer también frente a particulares que presten un servicio público; al respecto, Julio Estrada, Alexei, La eficacia de los derechos fundamentales entre particulares, Op. cit., pp. 234-235.
} 
privativos (artículos 14 y 16), al principio de legalidad en materia penal, al derecho de ser presumido inocente hasta que se demuestre lo contrario, al derecho a la tutela judicial efectiva (artículo 17), las características de la pena privativa de la libertad (artículo 18), la prohibición de las multas excesivas o de las penas infamantes e inusitadas (artículo 22), y así por el estilo.

De lo que se ha expuesto en el presente apartado cabe sacar dos conclusiones: a) será la Constitución la que a través del contenido semántico de sus preceptos nos permita sostener que un derecho fundamental se aplica o no a los particulares y, en caso afirmativo, de qué manera puede darse esta aplicación; b) del somero repaso que emprendimos se puede afirmar que hay derechos que claramente se aplican a las relaciones entre particulares (de hecho, hay algunos que se aplican a tales relaciones de forma casi exclusiva) y otros que no les resultan en modo alguno aplicables. Las dos conclusiones cobran sentido siempre que se parta de una idea difícilmente discutible: la Constitución es la norma suprema del ordenamiento jurídico $y$, en esa virtud, no puede haber comportamiento o norma alguna que le sea contraria.

\section{El lugar del principio de autonomía de la voluntad}

Lo anterior no obsta para reconocer la importancia del principio de autonomía de la voluntad, el cual es un eje vertebrador imprescindible para la articulación de las relaciones entre particulares. A partir del reconocimiento de este principio hay que mantener y defender el hecho de que habrá situaciones en las que los particulares pueden autodeterminarse como mejor les parezca. Como afirma Bilbao: "A nadie se puede obligar a organizar su vida privada con arreglo a los valores constitucionales. Es el precio que hay que pagar por preservar una sociedad de hombres libres y responsables, con una capacidad real de autodeterminarse." ${ }^{23}$ Lo importante desde un punto de vista práctico, en este contexto, es determinar hasta dónde llega esa capacidad de autoorganización que proviene del reconocimiento de que todos somos libres y responsables, y hasta dónde llega la vinculación del texto constitucional respecto a los particulares.

Un elemento interesante para determinar la manera en que los derechos fundamentales en tensión pueden armonizarse, con vista a decidir en

${ }^{23}$ Bilbao Ubillos, Juan María, La eficacia de los derechos fundamentales frente a particulares. Análisis de la jurisprudencia del Tribunal Constitucional, Op. cit., p. 362. 
un caso concreto si un derecho debe prevalecer sobre todo, lo constituye el hecho de que estemos en presencia de relaciones asimétricas entre los sujetos de la relación jurídica. ${ }^{24}$ Es decir, podríamos convenir en que la autonomía de la voluntad tiene un mayor espacio cuando la relación jurídica se establece entre sujetos ubicados en un plano de igualdad real; pero si esa simetría de poder no se presenta, y por el contrario una de las partes tiene elementos suficientes para forzar o doblegar la voluntad de la otra, entonces será posible imponer con mayor fuerza la eficacia horizontal de los derechos fundamentales.

De la misma forma, la autonomía de la voluntad no podría ser tan amplia en los casos en que se restrinja el acceso a una persona a un bien socialmente escaso; por ejemplo, cuando se trata del único servicio público de su tipo que se encuentra en una comunidad. Pensemos en el caso de una instalación para practicar la natación, la cual está en manos de un particular que decide no permitir la entrada de las mujeres. En ese caso es obvio que la libertad de asociación y la libertad de trabajo deben ceder frente al principio de no discriminación, aplicado a una relación jurídica entre particulares. ${ }^{25}$

En el caso concreto de la prohibición de discriminar contemplada en el párrafo tercero del artículo 1 constitucional, la eficacia entre particulares existiría, por mencionar algunos ejemplos, cuando una persona preste servicios que son financiados o subsidiados por el Estado, cuando ejerza profesiones reguladas por ley o para cuyo ejercicio se requiere de licencia, cuando esté a cargo de servicios u ocupaciones en los que se encuentren empleadas un gran número de personas y cuando se trate de la prestación de servicios escasos o que estén a cargo de otras personas, económicamente poderosas. ${ }^{26}$

Desde luego, está fuera de discusión que la autonomía de la voluntad debe ceder siempre que esté en juego la dignidad de la persona humana. Es decir, si mediante el pretexto de la autonomía de la voluntad se pretende cubrir una ofensa manifiesta, humillante, claramente anuladora de la dignidad de una persona, los derechos fundamentales deben entrar en acción para invalidar el acto o reparar la violación, según sea el caso. Podrían ubicarse en este ejemplo las condiciones de trabajo esclavizantes, ya

\footnotetext{
${ }^{24}$ Ibid., p. 368.

${ }^{25}$ En el apartado dedicado al análisis de la aplicación horizontal de los derechos fundamentales en el derecho comparado pondremos algunos otros ejemplos reales, tomados de la experiencia de otros países que coinciden con lo que se acaba de decir.

${ }^{26}$ Bilbao Ubillos, Juan María, Op. cit., p. 400.
} 
sea por lo prolongado de los horarios, por lo insalubre de las condiciones del lugar de trabajo o incluso por la desproporción evidente entre la tarea realizada y el salario que se paga al trabajador.

\section{iv. Desarkollo jurisprudencial}

En México la jurisprudencia tradicional ha establecido muy pocos criterios interpretativos en los que se reconozcan los efectos horizontales de los derechos fundamentales. Esto ha sido consecuencia, como ya se apuntaba, de la concepción que históricamente se ha tenido de los propios derechos (llamados, con la terminología del siglo xIx, "garantías individuales"), la cual además se ha proyectado a un concepto articulador de todo el sistema del derecho de amparo, que es el concepto de "autoridad para efectos del amparo”. Sin embargo, hay algunas tesis que pueden ser de interés para el tema que estamos estudiando.

Las tesis relevantes, a la vista de lo anterior, serían las siguientes:

Novena Época, Segunda Sala, Semanario Judicial de la Federación y su Gaceta, Tomo XXI, marzo de 2005, p. 359, tesis 2a. XXVII/2005, aislada, Administrativa.

Rubro: POSESIÓN. DIMENSIONES DE SU TUTELA CONSTITUCIONAL.

Texto: La Constitución Política de los Estados Unidos Mexicanos protege la posesión entre particulares (dimensión horizontal) y entre éstos y los poderes públicos (dimensión vertical), al reconocer en su artículo 14, segundo párrafo, que: "Nadie podrá ser privado de la vida, de la libertad o de sus propiedades, posesiones o derechos", sino bajo las condiciones que éste prevé, exigiendo de los particulares un deber de no afectación, garantizado a través de la obligación positiva de los poderes públicos de impedir la violación injustificada del derecho de posesión de otros, si se toma en cuenta que el primer párrafo del artículo 17 de la Constitución Federal señala que: "Ninguna persona podrá hacerse justicia por si misma, ni ejercer violencia para reclamar su derecho." En tal virtud, existe el deber de los poderes públicos de proteger la posesión y los derechos que de ella deriven frente a intromisiones injustificadas, a fin de que adquiera eficacia juridica dicha garantía individual en ambas dimensiones.

Precedentes: Contradicción de tesis 131/2003-ss. Entre las sustentadas por Ios Tribunales Colegiados Primero del Décimo Octavo Circuito y Tercero del Sexto Circuito, en contra del Segundo Tribunal Colegiado del Décimo Octavo Circuito. 21 de enero de 2005. Cinco votos. Ponente: Margarita Beatriz Luna Ramos. Secretario: Fernando Silva García.

Esta tesis es importante porque se refiere a un derecho (la posesión) que es objeto de protección constitucional en los artículos 14 y 16 y porque ade- 
más distingue explícitamente entre la "dimensión horizontal" y la "dimensión vertical” del derecho. Lo curioso de la tesis es que desprende algunas consecuencias llamativas una vez que establece las dos dimensiones del derecho a la posesión. En efecto, de la doble dimensionalidad del derecho la Corte desprende un deber para los poderes públicos: concretamente, el deber de proteger la posesión frente a intromisiones injustificadas.

Se trata de un ejemplo paradigmático de que la teoría ha llamado la "eficacia horizontal indirecta" de los derechos, que es aquella que no traslada consecuencias jurídicas directamente a los particulares, sino que se refiere al deber de las autoridades de evitar que los mismos consumen violaciones a los derechos fundamentales. Este criterio arroja como consecuencia que la eficacia horizontal esté mediatizada (por decirlo de alguna manera) por los poderes públicos, y singularmente por el poder judicial, ${ }^{27}$ que es frente a quien se podrá impugnar o demandar la violación que un particular lleve a cabo de un derecho fundamental de otro particular. A esta visión se le ha llamado también "tesis de la eficacia mediata" de los derechos fundamentales frente a particulares. ${ }^{28}$

Novena Época, Tribunales Colegiados de Circuito, Semanario Judicial de la Federación y su Gaceta, Tomo Xx, diciembre de 2004, p. 1413, tesis I.150.A.13 A, aislada, Administrativa.

Rubro: PROTECCIÓN A LA SALUd DE LOS NO FUMADORES EN EL DISTRITO FEDERAL. LA OBLIGACIÓN QUE LA LEY RELATIVA IMPONE EN SU ARTICULO 30., FRACCIÓN I, A LOS PROPIETARIOS, POSEEDORES O RESPONSABLES Y EMPLEADOS DE LOS LOCALES Y ESTABLECIMIENTOS CERRADOS, DE COADYUVAR ACTIVAMENTE EN LA VIGILANCIA DE SU CUMPLIMIENTO, NO VIOLA LOS PRINCIPIOS DE LEGALIDAD Y SEGURIDAD JURÍDICA CONTENIDOS EN LOS ARTICULOS 14 Y 16 CONSTITUCIONALES.

Texto: La Suprema Corte de Justicia de la Nación ha establecido en diversos precedentes que esos principios son respetados por las autoridades legislativas cuando, además de actuar dentro de los límites que constitucionalmente les fueron conferidos (fundamentación) y de emitir leyes referidas a relaciones sociales que reclaman ser jurídicamente reguladas (motivación), las disposiciones de observancia general que emiten, por una parte, crean certidumbre en los gobernados sobre las consecuencias de su conducta y, por otra, tratándose de normas que confieren alguna facultad a una autoridad, acotan en la medida necesaria y razonable esa atribución, en forma tal que impida a la res-

\footnotetext{
${ }^{27}$ Aunque entre los teóricos de la eficacia horizontal se discute si en esta tarea debe tener preeminencia el juez o el legislador, es decir, se discute si debe ser a través de la ley o a través de las sentencias y la jurisprudencia la forma en que se "reciben" y corrigen las violaciones a los derechos fundamentales cometidas por particulares. La experiencia comparada, en este punto, admite ambas soluciones, si bien es cierto que la intervención judicial -en un momento o en otro- siempre termina siendo necesaria.

${ }^{28}$ Mijangos y González, Javier, La vigencia de los derechos fundamentales en las relaciones entre particulares, Op. cit., pp. 18ss; Bilbao Ubillos, Juan María, Op. cit., pp. 325ss.
} 
pectiva autoridad actuar de manera arbitraria o caprichosa en atención a las normas a las que debe sujetarse al ejercer dicha potestad. En esa tesitura, la circunstancia de que en el artículo 30., fracción I, de la ley de que se trata, se establezca que los propietarios, poseedores o responsables y empleados de los locales y establecimientos cerrados que el propio ordenamiento señala, deben coadyuvar activamente en la vigilancia del cumplimiento de ésta, no viola esos principios constitucionales, porque este deber no implica de manera alguna que se deleguen en dichos sujetos las atribuciones y obligaciones que el mismo ordenamiento impone en su artículo 20., al jefe de Gobierno del Distrito Federal a través de los órganos políticos administrativos de las demarcaciones territoriales y las instancias administrativas correspondientes, en sus respectivos ámbitos de competencia, de aplicar y vigilar el cumplimiento de la ley, ya que la coadyuvancia no debe interpretarse como la subrogación de los particulares al principio de autoridad y vigilancia, pues la autoridad no pierde la potestad del ejercicio de sus facultades. La colaboración de los particulares en ese aspecto sólo significa una ayuda o cooperación para la vigilancia en el cumplimiento de la ley, lo cual atiende a la posición que guardan los propietarios, poseedores, responsables y empleados de los locales y establecimientos cerrados frente a los sujetos transgresores de la ley, que fumen tabaco en lugares prohibidos, ya que resulta materialmente imposible que las autoridades competentes supervisen permanentemente cada uno de los locales o establecimientos para verificar que se acaten tales disposiciones, situación que de alguna manera previó el legislador, y por ello impuso a las personas que de manera directa atiendan esos lugares, para que coadyuven en la aplicación y observancia del mandato legal. Además, cabe destacar que las obligaciones que la ley relativa impone a los propietarios, poseedores o encargados de los establecimientos mercantiles, son deberes que pueden catalogarse como propios de una cooperación de los particulares en la realización de los fines del Estado, circunstancia que en la legislación positiva mexicana está plenamente permitida.

DÉCIMO QUINTO TRIBUNAL COLEGIADO EN MATERIA ADMINISTRATIVA DEL PRIMER CIRCUITO.

Precedentes: Amparo en revisión 54/2004. Operadora Bros, S.A. de C.V. 22 de septiembre de 2004. Unanimidad de votos. Ponente: Armando Cortés Galván. Secretario: José Álvaro Vargas Ornelas.

El tema en cuestión en esta tesis es el derecho a la salud. Ése es el derecho al que busca proteger la ley que fue reclamada en amparo y que ordena a los particulares que supervisen ciertos aspectos de su cumplimiento. Aunque no se trata de un caso claro de eficacia horizontal, la cita de la tesis es interesante -creo- debido a que involucra a los particulares en una tarea de protección de un derecho fundamental (la salud), frente a otros particulares. De esta manera, tanto la ley como la tesis transcrita parecen aceptar que los derechos fundamentales pueden tener ciertos aspectos de los que se desprendan "deberes" u obligaciones para los particulares. En el 
caso concreto de los particulares dueños de establecimientos mercantiles, para el efecto de que sean ellos quienes hagan observar la normativa que protege la salud de sus clientes, frente a los actos de otros particulares (que pueden ser clientes o empleados del propio establecimiento mercantil). ${ }^{29}$

\author{
Sexta Época \\ Instancia: Cuarta Sala \\ Fuente: Semanario Judicial de la Federación y su Gaceta \\ Tomo: Quinta Parte, LxIX \\ Página: 10. \\ ARTíCULO 14 CONSTITUCIONAL. DEBE SER RESPETADO NO SÓLO POR LAS AUTORIDADES, SINO TAMBIÉN \\ POR LOS PARTICULARES. Ferrocarriles. El artículo 14 de la Constitución Federal, debe ser \\ respetado no sólo por las autoridades, sino también por los particulares u orga- \\ nizaciones privadas de toda indole, toda vez que si conforme a dicha garantía \\ individual, para la aplicación de toda sanción o la privación de un derecho, \\ mediante acto de autoridad, es menester que la persona afectada fuere previa-
}

\footnotetext{
${ }^{29}$ Una tesis relacionada con la que se acaba de transcribir, que también es interesante para nuestro tema de estudio, es la siguiente:

Novena Época, Tribunales Colegiados de Circuito, Semanario Judicial de la Federación y su Gaceta, Tomo xxı, mayo de 2005, p. 1354, tesis 1.7o.A. J/24, jurisprudencia, Administrativa.

Rubro: PROTECCIÓN A LA SALUD DE LOS NO FUMADORES EN EL DISTRITO FEDERAL. EL ARTICULO 16 DE LA LEY RELATIVA, AL CONSIDERAR RESPONSABLES SUBSIDIARIOS A QUIENES NO COADYUVEN CON LA AUTORIDAD PARA HACER CUMPLIR SUS DISPOSICIONES, NO VIOLA LA GARANTIA DE SEGURIDAD JURIDICA PREVISTA EN LOS ARTICULOS 14 Y 16 DE LA CONSTITUCIÓN FEDERAL.

Texto: El artículo 16 de la Ley de Protección a la Salud de los No Fumadores en el Distrito Federal, que prevé la responsabilidad subsidiaria de los propietarios, poseedores o responsables de los locales y establecimientos, por no coadyuvar con la autoridad para hacer cumplir la norma, no contraviene los artículos 14 y 16 de la Constitución Política de los Estados Unidos Mexicanos, pues, todo ciudadano tiene la obligación de coadyuvar con la autoridad para lograr el cumplimiento de la ley; de tal suerte que las obligaciones establecidas en el citado precepto no deben entenderse como una violación a la seguridad jurídica, pues en el procedimiento que ese mismo artículo prevé, se desprende que el propietario, poseedor o responsable de un local o establecimiento deberá exhortar a quien fume fuera de las áreas autorizadas a que se abstenga de hacerlo o proceda a trasladarse a los lugares destinados para tal fin; que en caso de negativa, le invitará a abandonar las instalaciones; si se resiste, deberá solicitar el auxilio de un elemento de la fuerza pública, a efecto de que ponga al infractor a disposición del Juez Cívico competente, concluyendo con tal proceder su responsabilidad. De ahí que la responsabilidad del particular sujeto a la norma es una consecuencia directa de no actuar conforme lo dispone la propia legislación.

SÉPTIMO TRIBUNAL COLEGIADO EN MATERIA ADMINISTRATIVA DEL PRIMER CIRCUITO.

Precedentes: Amparo en revisión 2607/2004. Hotel Flamingos Plaza, S.A. de C.V. 11 de agosto de 2004. Unanimidad de votos. Ponente: Alberto Pérez Dayán. Secretaria: María del Carmen Alejandra Hernández Jiménez.

Amparo en revisión 2357/2004. Manuel lgnacio Corral Mier. 18 de agosto de 2004. Unanimidad de votos. Ponente: Alberto Pérez Dayán. Secretaria: Silvia Fuentes Macías.

Amparo en revisión 2777/2004. Paraíso Perisur, S.A. de C.V. 18 de agosto de 2004. Unanimidad de votos. Ponente: Alberto Pérez Dayán. Secretaria: María del Carmen Alejandra Hernández Jiménez.

Amparo en revisión 2807/2004. Chalet Suizo, S.A. de C.V. y otras. 18 de agosto de 2004. Unanimidad de votos. Ponente: Alberto Pérez Dayán. Secretaria: Amelia Vega Carrillo. Amparo en revisión 2747/2004. José Guadalupe Ríos Roldán. 22 de septiembre de 2004. Unanimidad de votos. Ponente: Adela Domínguez Salazar. Secretaria: Aurora del Carmen Muñoz García.
} 
mente oída y vencida en juicio, en el cual se satisfagan los requisitos esenciales del procedimiento, con más razón cuando la sanción la va a aplicar una organización de carácter privado como lo es el Sindicato de Trabajadores Ferrocarrileros de la República Mexicana, el cual no puede privar a sus agremiados, aun cuando para ello le autorizaren sus estatutos, de esa garantía constitucional que confiere el derecho de ser oido en defensa, de donde se infiere que para que un trabajador pueda ser expulsado del sindicato a que pertenece mediante la aplicación de la correspondiente cláusula de exclusión, es menester que el trabajador afectado haya sido citado para concurrir al juicio sindical respectivo, en el cual sea debidamente oído en defensa, dándosele la oportunidad de aportar las pruebas que estimare pertinentes, tendientes a desvirtuar los cargos en los que se pretende apoyar la expulsión, pues de no llenarse tales requisitos, es evidente que se priva al afectado de la garantía constitucional a que se ha venido haciendo mérito; si la Junta responsable no lo consideró así, puesto que estimó inoperante la acción de nulidad que ejercitó el demandante y hoy quejoso del procedimiento relativo a la aplicación en su perjuicio de la cláusula de exclusión, apoyando su fallo absolutorio en el inciso "c" adicionado al artículo 171 de los Estatutos que rigen la vida interna del Sindicato de Trabajadores Ferrocarrileros de la República Mexicana, no obstante que el procedimiento que señala ese inciso está en pugna con el texto del artículo 14 constitucional, puesto que priva a los miembros del sindicato de la garantía de audiencia que consigna dicha disposición constitucional, es de concluirse forzosamente que la Junta responsable al estimar inoperante las acciones ejercitadas en el juicio laboral y absolver a la parte demandada de tales prestaciones incurrió en las violaciones que se comentan.

Amparo directo 3855/62. Manuel Martínez Carrasco. 7 de marzo de 1963. Cinco votos. Ponente: Agapito Pozo.

Esta tesis, que fue emitida hace ya algunos años, durante la llamada "Sexta época” del Semanario Judicial de la Federación, tiene interés en la medida en que sin rodeos señala la obligación de los particulares de respetar el artículo 14 constitucional. La tesis se refiere específicamente al "Sindicato de Trabajadores Ferrocarrileros de la República Mexicana”, el cual debe respetar el derecho de audiencia que establece el mencionado artículo 14.

Hay que destacar el hecho de que con su decisión la Suprema Corte en ese momento decide imponer un derecho fundamental al interior de una organización, que es otro de los ejemplos clásicos de eficacia horizontal. $\mathrm{Al}$ hacerlo, la Corte reconoció la vinculación de los grupos sociales a los derechos fundamentales, sobre todo cuando se trata de grupos sociales que son vehículos necesarios para el ejercicio de un derecho fundamental (los sindicatos, en este sentido, tienen la función de permitir el ejercicio de la libertad sindical y de los derechos que son inherentes a tal libertad). Con 
el tiempo, un criterio parecido sería reconocido para el funcionamiento interno de los partidos políticos, si bien en este caso se trata de agrupaciones que el artículo 41 constitucional califica como de "interés público". ${ }^{30}$

Es importante que los jueces pongan especial énfasis en hacer que las organizaciones que pueden imponer su voluntad sobre otros particulares o que son el instrumento idóneo (o incluso único) para el ejercicio de ciertos derechos fundamentales, sean responsables por su eventual violación. Los derechos fundamentales, sin duda alguna, rigen también dentro de las organizaciones sociales de derecho público y -con ciertos matices, como ya se ha expresado- de derecho privado.

Comunicaciones privadas. El derecho a su inviolabilidad, consagrado en el artículo 16, párrafo noveno, de la Constitución Federal, es oponible tanto a las autoridades como a los gobernados, quienes al transgredir esta prerrogativa incurren en la comisión de un ilicito constitucional. Del análisis de lo dispuesto en diversos preceptos de la Constitución Política de los Estados Unidos Mexicanos, se advierte que la misma contiene mandatos cuyos destinatarios no son las autoridades, sino que establece deberes a cargo de los gobernados, como sucede, entre otros casos, de lo dispuesto en sus artículos 20, 4 o y 27, en los que la prohibición de la esclavitud, el deber de los padres de preservar el derecho de los menores a la satisfacción de sus necesidades y a la salud física y mental, así como los límites a la propiedad privada, constituyen actos u omisiones que deben observar aquéllos, con independencia de que el mandato constitucional constituya una garantía exigible a las autoridades y que, por ende, dentro de su marco competencial éstas se encuentren vinculadas a su acatamiento. En tal virtud, al establecer el Poder Revisor de la Constitución, en el párrafo noveno del artículo 16 de la Constitución General de la República, que las "comunicaciones privadas son inviolables", resulta inconcuso que con ello estableció como derecho fundamental el que ni la autoridad ni los gobernados pueden intervenir una comunicación, salvo en los casos y con las condiciones que respecto a las autoridades establece el propio numeral y, por tanto, la infracción de los gobernados a tal deber conlleva la comisión de un ilicito constitucional, con independencia de los efectos que provoque o del medio de defensa que se prevea para su resarcimiento, en términos de la legislación ordinaria correspondiente. (Tesis aislada. Semanario Judicial de la Federación y su Gaceta, Tomo XII, diciembre de 2000. Novena Época. Segunda Sala. Tesis 2a cLX/2000. p. 428.)

Comunicaciones privadas. Las pruebas ofrecidas dentro de un juicio civil, obtenidas por un gobernado sin respetar la inviolabilidad de aquéllas, constituyen un ilicito constitucional, por lo que resultan contrarias a derecho y no deben

${ }^{30}$ Al respecto, Castillo González, Leonel, Los derechos de la militancia partidista, TEPFJ, México, 2004. 
admitirse por el juzgador correspondiente. El artículo 16, párrafo noveno, de la Constitución Política de los Estados Unidos Mexicanos establece que las comunicaciones privadas son inviolables; que exclusivamente la autoridad judicial federal, a petición de la autoridad federal que faculte la ley o del titular del Ministerio Público de la entidad federativa correspondiente, podrá autorizar la intervención de cualquier comunicación privada; que dicha petición deberá ser por escrito, en la que se funden y motiven las causas legales de la solicitud, expresando el tipo de intervención, los sujetos de la misma y su duración; y que no se podrán otorgar estas autorizaciones cuando se trate de materias de carácter electoral, fiscal, mercantil, civil, laboral o administrativo, ni en el caso de las comunicaciones del detenido con su defensor. El párrafo décimo de dicho numeral señala que las intervenciones autorizadas se ajustarán a los requisitos y límites previstos en las leyes, y que los resultados de las intervenciones que no cumplan con éstos, carecerán de todo valor probatorio. Ante ello, debe estimarse que fue voluntad del Poder Revisor de la Constitución establecer como derecho fundamental la inviolabilidad de las comunicaciones privadas y, en contrapartida, la obligación exigible tanto a las autoridades como a los gobernados de respetar dicha prerrogativa, lo que da lugar a que si un gobernado realiza la intervención de alguna comunicación privada sin el consentimiento expreso e irrefutable de los que la entablan, incurrirá en un ilicito constitucional; por ende, si dentro de un juicio civil, en cualquiera de sus especies, una de las partes ofrece como prueba la grabación de una comunicación privada que no fue obtenida legalmente, tal probanza debe estimarse contraria a derecho y, por tanto, no debe admitirse por el juzgador correspondiente, pues ello implicaría convalidar un hecho que en sí mismo es ilícito. (Tesis aislada. Semanario Judicial de la Federación y su Gaceta, Tomo XII, diciembre de 2000. Novena Época. Segunda Sala. Tesis $2^{\text {a }}$ CLXI/2000. p. 428.)

Las dos tesis que se acaban de transcribir quizá son las más importantes para determinar la manera en que la eficacia horizontal de los derechos fundamentales puede ser recogida dentro del ordenamiento jurídico mexicano. En las dos tesis de la Segunda Sala de la Suprema Corte (derivadas de un asunto en el que el ministro ponente fue Guillermo Ortiz M.), se hace alusión a un concepto que podemos calificar como novedoso en nuestro panorama constitucional y que, bien empleado, puede generar importantes innovaciones hermenéuticas. Me refiero a la noción de "ilícito constitucional", que hace referencia -si mal no entiendo- a todos aquellos hechos jurídicos que se han producido violando una norma constitucional, con independencia del carácter público o privado (o incluso mixto) que tenga el sujeto activo o violador de la Carta Magna. De hecho, el concepto de ilícito constitucional se puede circunscribir un poco más, pues en el criterio de la Corte tal ilícito se produciría solamente cuando se viola un "deber constitucional". 
Las tesis provienen de un juicio de amparo interpuesto en un caso de la jurisdicción civil que trataba de un divorcio necesario. ${ }^{31}$ En el curso del juicio uno de los cónyuges presentó como prueba una cinta de audio del otro cónyuge en la que hablaba con una tercera persona. El cónyuge cuya voz se oía en la cinta promovió un juicio de amparo pidiendo que no fuera considerada como prueba la propia cinta en el juicio; el juez de amparo le dio la razón, pero su contraparte promovió un recurso de revisión que llegó al conocimiento de la Segunda Sala de la Suprema Corte en virtud de que se requería de una interpretación directa del artículo 16 constitucional.

En esa oportunidad, como ya se ha dicho, la Corte introduce el concepto de "ilícito constitucional", que como acertadamente lo destaca Mijangos, no tiene precedentes en nuestra jurisprudencia constitucional ni tampoco a nivel doctrinal. ${ }^{32}$ Por ilícito constitucional la Corte entiende la omisión de los actos ordenados o la ejecución de los actos prohibidos por la Constitución. Es importante destacar que la Corte señala que un ilícito constitucional puede ser cometido tanto por autoridades como por particulares "con total independencia del procedimiento que se prevea para el resarcimiento correspondiente"; es decir, la Corte distingue la cuestión sustantiva (lo que Mijangos llama "el problema de construcción") de la cuestión procesal (llamada por el mismo autor el "problema de la protección"), ${ }^{33}$ lo cual es muy adecuado para hacer planteamientos correctos sobre la eficacia horizontal de los derechos fundamentales.

La consecuencia de los criterios referidos, como consta expresamente en la segunda de las tesis que estamos comentando, es que si una prueba fue obtenida a través de la comisión de un ilícito constitucional, no puede ser tomada en cuenta por juez alguno en un procedimiento jurisdiccional. ${ }^{34}$

Lo importante, a partir de las tesis citadas, es que la Corte ya asume con todas sus consecuencias la eficacia entre particulares al menos de ciertos derechos fundamentales. Este criterio se proyecta de forma inme-

\footnotetext{
${ }^{31}$ La exposición de los detalles en Mijangos y González, Javier, Op cit., pp. 62ss. El mismo autor ha analizado el caso en su ensayo "El amparo en revisión 2/2000: una puerta hacia la incidencia de las garantías individuales en las relaciones entre particulares”, Revista del Instituto de la Judicatura Federal, número 14, México, 2003.

${ }_{32}$ Mijangos y González, Javier, La vigencia de los derechos fundamentales en las relaciones entre particulares, 0 p. cit., p. 63.

${ }^{33}$ Ibid., p. 65.

${ }^{34}$ El criterio sobre la inadmisibilidad judicial de las pruebas obtenidas ilícitamente es muy conocido en los ordenamientos jurídicos modernos. Algunos países lo han elevado incluso a rango constitucional, tal es el caso de la Constitución brasileña de 1988, cuyo artículo 5 dispone en la fracción uvi que "son inadmisibles en el proceso las pruebas obtenidas por medios ilícitos". Esta concepción permite extender la eficacia horizontal de los derechos fundamentales al ámbito probatorio.
} 
diata hacia todas las autoridades judiciales del país (por mandato de los artículos 192 y siguientes de la Ley de Amparo), pero puede ser de gran utilidad también para los órganos administrativos, que pueden aplicar esa jurisprudencia en un buen número de procedimientos.

\section{Derecho comparado y derecho internacional DE LOS DERECHOS HUMANOS}

Como se ha puesto en evidencia en varios de los apartados anteriores, la experiencia mexicana acerca de la aplicación entre particulares de los derechos fundamentales es muy escasa. Se trata de un tema que solamente de forma muy incipiente ha sido objeto de pronunciamientos jurisprudenciales y de análisis teóricos. En este contexto, quizá puede ser útil mencionar algunas experiencias tomadas del derecho comparado, tanto en el ámbito del derecho nacional de otros países como en el del derecho internacional de los derechos humanos. No se trata de hacer un recuento completo del derecho comparado en esta materia, sino de resaltar las experiencias que pueden tener mayor interés para el caso mexicano.

La mejor forma de zanjar las discusiones sobre los efectos horizontales de los derechos fundamentales consiste en disponer por mandato constitucional tales efectos. Esto es lo que hace, por ejemplo, la Constitución de Portugal de 1976, cuyo artículo 18.1 señala: "Los preceptos constitucionales relativos a los derechos, libertades y garantías son directamente aplicables y vincularán a las entidades públicas y privadas."

Otros textos constitucionales prefieren reconocer la procedencia de acciones judiciales (de amparo o de un tipo parecido) por actos de particulares que presuntamente violen derechos fundamentales. Éste es el caso de la Constitución de Argentina, que luego de la reforma integral de 1994, dispone en su artículo 43: "Toda persona puede interponer acción expedita y rápida de amparo, siempre que no exista otro medio judicial más idóneo, contra todo acto $\mathrm{u}$ omisión de autoridades públicas o de particulares..." ${ }^{35}$ Disposiciones parecidas se encuentran en un buen número de las constituciones de las provincias que integran el Estado argentino. ${ }^{36}$

En sentido parecido, la Constitución de Colombia de 1991 establece en

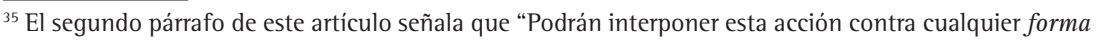
de discriminación...”

${ }^{36}$ La enumeración de las mismas puede verse en Valadés, Diego, La protección de los derechos fundamentales frente a particulares, $0 p$. cit., pp. 22-23. 
el último párrafo de su artículo 86: "La ley establecerá los casos en que la acción de tutela procede contra particulares encargados de la prestación de un servicio público o cuya conducta afecte grave y directamente el interés colectivo, o respecto de quienes el solicitante se halle en estado de subordinación o de indefensión." La mejor doctrina constitucional colombiana ha señalado que, pese al avance que este precepto representa, en realidad confía el tema de la eficacia horizontal a la competencia del legislador, lo cual pone de manifiesto lo excepcional que es la oposición de los derechos fundamentales frente a los particulares. ${ }^{37}$

Con todo, el artículo 86 de la Constitución colombiana es interesante porque a pesar de que se dirige en primer término a una cuestión procesal (referida a la procedencia de la acción de tutela), en realidad incide también en aspectos sustantivos cuando enumera algunos supuestos específicos, que sin duda tienen una alta relevancia para la aplicación horizontal de los derechos fundamentales.

En efecto, que los derechos fundamentales puedan hacerse valer frente a particulares que prestan servicios públicos es un tema de la mayor importancia a la luz de los grandes procesos de privatización de servicios públicos que se han dado en muchos países de América Latina, incluyendo el caso de México. ${ }^{38}$

Suele suceder que los estados se reserven la titularidad de algún servicio público, pero trasladen a los particulares su prestación; en estos casos, si bien formalmente se trata de simples particulares, los derechos fundamentales deben valer debido a la función de interés público que llevan a cabo - por un lado- y debido a las medidas que pueden desarrollar frente a otros particulares, respecto de las cuales sería muy ingenuo pensar que se dan relaciones simétricas e iguales entre los sujetos involucrados.

La aplicación jurisprudencial que del mandato del artículo 86 que estamos comentando ha hecho la Corte Constitucional colombiana, permite advertir dos principios hermenéuticos: a) "el particular que presta un servicio público se equipara a la autoridad pública y por ende es destinatario de la acción de tutela en los mismos supuestos en que lo es la autoridad

\footnotetext{
${ }^{37}$ Julio Estrada, Alexei, La eficacia de los derechos fundamentales entre particulares, Op. cit., pp. 229230. El desarrollo legislativo del artículo 86 fue realizado por medio del Decreto ley 2591 de 1991, que a la postre fue declarado parcialmente inconstitucional, debido a que limitaba algunos de los supuestos señalados por el precepto de la Constitución.

${ }^{38}$ Ingo Von Münch sostiene que "La privatización de los servicios públicos, por ejemplo telecomunicaciones o universidades, reducirá el ámbito de aplicación del derecho público y, simultáneamente, ampliará el ámbito de aplicación del derecho privado. En la misma proporción, se expandirá la drittwirkung. Cfr. "Drittwirkung de derechos fundamentales en Alemania”, Op. cit., p. 32.
} 
pública, es decir, ante la violación de cualquier derecho fundamental”; y b) sin importar de qué servicio público se trate, cabe la acción de tutela en contra del particular encargado de su prestación. ${ }^{39}$

Los otros dos supuestos señalados por el artículo 86 de la Constitución colombiana también son muy importantes. Se trata, en primer lugar, del caso en que un particular con su conducta afecte grave y directamente el interés colectivo. En tal supuesto pueden encontrarse las empresas contaminantes ${ }^{40} \mathrm{o}$ los particulares que afecten el patrimonio urbano, histórico o artístico. ${ }^{41}$

La tercera previsión del artículo 86 se refiere a las relaciones jurídicas en que una persona se halle en estado de subordinación o de indefensión; se puede aplicar este supuesto a las relaciones de los particulares con las grandes corporaciones, que tampoco pueden considerarse como simétricas (por ejemplo cuando las corporaciones imponen la firma de contratos "de adhesión", en los cuales las cláusulas están determinadas por una de las partes y respecto de las cuales la otra parte solamente puede someterse o no participar en la relación jurídico-contractual). La Corte Constitucional colombiana ha sostenido que la subordinación y la indefensión son características fácticas que deben ser precisadas caso por caso. ${ }^{42}$

Regulaciones semejantes a las de Argentina y Colombia pueden encontrarse en otros textos constitucionales de América Latina, como los de Bolivia, Chile, Ecuador, Paraguay y Perú. ${ }^{43}$

Los casos que acabamos de comentar se refieren a previsiones establecidas directamente por los textos constitucionales. Sin embargo, la doctrina de la eficacia horizontal de los derechos fundamentales ha sido desarrollada en muchos países a través de criterios jurisprudenciales (como en el caso de México, según lo que ya vimos en el apartado anterior). Conviene mencionar los pronunciamientos más conocidos.

${ }^{39}$ Julio Estrada, Alexei, La eficacia de los derechos fundamentales entre particulares, Op. cit., pp. 235-236.

${ }^{40}$ La corte constitucional ha emitido sentencias referidas a ruidos molestos producidos por establecimientos de diversión o por empresas que trabajan cerca de zonas residenciales, por emisión de malos olores, por el vertido de desechos químicos, etcétera. Julio Estrada, Alexei, La eficacia de los derechos fundamentales entre particulares, $0 p$. cit., p. 241.

${ }^{41}$ Aunque en el caso de Colombia su utilización está limitada ya que existe en su ordenamiento jurídico otra vía procesal de protección de este tipo de intereses o bienes jurídicos, que son las acciones populares previstas en el artículo 88 de su Constitución.

42 Julio Estrada, Alexei, $O p$. cit., pp. 244ss.

${ }^{43}$ Valadés, Diego, La protección de los derechos fundamentales frente a particulares, Op. cit., pp. 28-29; Fix Zamudio, Héctor, Ensayos sobre el derecho de amparo, $3^{a}$ edición, México, Porrúa-unAm, 2003, p. 788. 
El caso quizá más citado sobre nuestro tema (o al menos uno de los más difundidos) fue resuelto en 1958 por el Tribunal Constitucional Federal de Alemania, y se le conoce como "Caso Lüth". ${ }^{44}$ Su origen se encuentra en la exhortación que un particular hizo para que el público boicoteara una película realizada por otro particular. El primero de ellos fue demandado civilmente y condenado por los tribunales ordinarios. Al conocer del recurso extraordinario el Tribunal Constitucional afirma que la Constitución alemana "no tiene el carácter de un ordenamiento de valores neutral"; por el contrario, el orden de valores que impone la Constitución, el cual "encuentra su punto medio al interior de la comunidad social, en el libre desarrollo de la personalidad y la dignidad del ser humano, como decisión constitucional fundamental, debe ser válido para todas las esferas del derecho; la legislación, la administración y la jurisdicción reciben de él directrices e impulso. Así influye evidentemente también en el derecho civil; ninguna prescripción jurídico-civil puede estar en contradicción con él". ${ }^{45}$

En el ámbito de América Latina destaca el pronunciamiento de la Corte Suprema de Argentina en el conocido como "Caso Kot". En este caso la Corte reconoció que los derechos fundamentales de un empresario podían ser violados por un grupo social determinado (en el caso concreto se trataba de un sindicato). En la sentencia relativa la Corte sostuvo que:

\begin{abstract}
Además de los individuos humanos y del Estado, hay ahora una tercera categoría de sujetos, con o sin personalidad jurídica, que sólo raramente conocieron los siglos anteriores: Ios consorcios, los sindicatos, las asociaciones profesionales, las grandes empresas, que acumulan casi siempre un enorme poder material o económico. A menudo sus fuerzas se oponen a las del Estado y no es discutible que estos entes colectivos representan, junto con el progreso material de la sociedad, una fuente de amenazas para el individuo y sus derechos esenciales... ${ }^{46}$
\end{abstract}

Este caso tuvo importantes repercusiones para la configuración del juicio de amparo en Argentina, tanto a nivel federal como provincial, así como en otros países de la región. ${ }^{47}$

\footnotetext{
${ }^{44}$ Un análisis del caso y del debate que suscitó posteriormente en la dogmática constitucional alemana puede verse en Julio Estrada, Alexei, La eficacia de los derechos fundamentales entre particulares, Op. cit., pp. 68ss.

${ }^{45}$ Los pasajes más importantes de la sentencia se encuentran en traducción al español en la obra de Schwabe, Jürgen, Cincuenta años de jurisprudencia del Tribunal Constitucional Federal alemán, Fundación K. Adenauer, Bogotá, 2003, pp. 133-137.

${ }^{46}$ Texto tomado de Fix Zamudio, Héctor, "La protección jurídica y procesal frente a los grupos de presión" en el libro del mismo autor, Protección jurídica de los derechos humanos. Estudios comparativos, $2^{\text {a }}$ edición, México, CNDH, 1999, pp. 161-162.

${ }^{47}$ Fix Zamudio, Héctor, Ensayos sobre el derecho de amparo, Op. cit., pp. 786ss.
} 
En Estados Unidos la Suprema Corte ha mantenido un criterio parecido al que ya hemos citado de los tribunales mexicanos, en el sentido de reconocer que la afectación de los derechos fundamentales solamente se presenta cuando existe un "acto de autoridad"; el concepto empleado en Estados Unidos es el de state action..$^{48}$ En ausencia de esa acción estatal no puede demandarse la violación de un derecho fundamental.

Sin embargo, de forma indirecta se han podido obtener algunos pronunciamientos que al menos han reconocido fenómenos discriminatorios por parte de los particulares o violaciones del derecho de asociación. Entre los más importantes en esta materia se encuentra la sentencia del caso Roberts versus United States Jaycees de 1984, sobre la no admisión de mujeres en ciertas asociaciones privadas. En un caso parecido (Board of Directors of Rotary International versus Rotary Club of Duarte, de 1987) la Corte impuso la obligación de los clubs de Rotarios (muy conocidos en Estados Unidos y en México) de aceptar a mujeres; es decir, en ambos casos la Corte sostuvo que la discriminación por razón de sexo no puede imponerse frente al derecho de libre asociación. El mismo criterio fue sostenido, con diversos matices, en casos posteriores. ${ }^{49}$

En otras sentencias la Corte de los Estados Unidos ha declarado la inconstitucionalidad de normativas locales de desarrollo urbano que exigían o permitían la segregación racial en la urbanización de barrios. Un pronunciamiento pionero en este tema se encuentra en la sentencia del caso Buchanan versus Warley de 1917. La extensión de este criterio a actos de particulares no sucedió, sin embargo, sino hasta 1968, cuando en la sentencia del caso Jones versus Alfred H. Mayer Co. la Corte sostuvo que la discriminación racial estaba prohibida tanto para las autoridades como para los particulares (el caso se había originado por la negativa del propietario de una vivienda para vender la misma a una pareja, dado que el marido era una persona afroamericana). ${ }^{50}$

A nivel internacional, la jurisprudencia de la Corte Interamericana de Derechos Humanos ha reconocido también la eficacia entre particulares de los derechos fundamentales en varios de sus pronunciamientos, tanto

${ }^{48}$ Un análisis de este concepto y los matices con que ha sido aplicado por los tribunales estadounidenses puede verse en Bilbao Ubillos, Juan Maria, Los derechos fundamentales en la frontera entre lo público y lo privado, McGraw-Hill, Madrid, 1997.

${ }^{49} \mathrm{Cfr}$. al respecto, O'Connor, Karen, "Private discriminatory associations" en The Oxford Companion to the Supreme Court of the United States, 2a edición, Oxford University Press, Nueva York, 2005, pp. 786-787.

${ }^{50}$ Una narración de estos y otros precedentes puede verse en Rosenberg, Gerald N., "Housing discrimination" en The Oxford Companion to the Supreme Court of the United States, Op. cit., pp. 475-476. 
en sentencias como en opiniones consultivas. ${ }^{51}$ En concreto, la Corte considera que el Estado debe hacer valer los derechos fundamentales en las relaciones sujetas al derecho privado, pues de otra manera podrian darse violaciones de derechos que le supondrían, llegado el caso, incurrir en una responsabilidad internacional. La Corte afirma, a propósito de los derechos de los trabajadores, que: "En una relación laboral regida por el derecho privado, se debe tener en cuenta que existe una obligación de respeto de los derechos humanos entre particulares. Esto es, de la obligación positiva de asegurar la efectividad de los derechos humanos protegidos, que existe en cabeza de los estados, se derivan efectos en relación con terceros (erga omnes). Dicha obligación ha sido desarrollada por la doctrina jurídica y, particularmente, por la teoría del drittwirkung, según la cual los derechos fundamentales deben ser respetados tanto por los poderes públicos como por los particulares en relación con otros particulares" (Opinión Consultiva número 18, párrafo 140).

En el mismo sentido, la Corte considera que: "La obligación impuesta por el respeto y garantía de los derechos humanos frente a terceros se basa también en que los Estados son los que determinan su ordenamiento jurídico, el cual regula las relaciones entre particulares y, por lo tanto, el derecho privado, por lo que deben también velar para que en esas relaciones privadas entre terceros se respeten los derechos humanos, ya que de lo contrario el Estado puede resultar responsable de la violación de esos derechos (OC 18, párrafo 147).

En un pronunciamiento muy parecido, dentro de un caso contencioso, la Corte ha sostenido que "un hecho ilícito violatorio de los derechos humanos que inicialmente no resulte imputable directamente a un Estado, por ejemplo por ser obra de un particular o por no haberse identificado al autor de la agresión, puede acarrear responsabilidad internacional del Estado, no por ese hecho en sí mismo sino por falta de la debida diligencia para prevenir la violación o para tratarla en los términos requeridos por la Convención (Americana de Derechos Humanos)”. 52

Vover al Índice>>

\footnotetext{
${ }^{51}$ Los criterios jurisprudenciales de la Corte Interamericana tienen un especial interés para México, ya que resultan obligatorios en términos del artículo 133 constitucional y de la tesis 77/99 del Pleno de la Suprema Corte de Justicia de la Nación, así como de los preceptos correspondientes de la Convención de Viena sobre derecho de los tratados y de la propia Convención Americana de Derechos Humanos que fue el instrumento de creación de la Corte.

${ }^{52}$ Caso Velásquez Rodríguez, párrafo 173, consultable en García Ramírez, Sergio (Coord.), La jurisprudencia de la Corte Interamericana de Derechos Humanos, México, IIJ-unam, 2001, p. 81.
} 